\title{
Bile Acid Excretion: the Alternate Pathway
}

\section{in the Hamster}

\author{
Renato Galeazzi and Norman B. JavitT \\ From the Division of Gastroenterology, Department of Medicine, New York Hospital-Cornell \\ Medical Center, New York 10021
}

\begin{abstract}
A B S T R A C T The quantitative significance of renal excretion of bile acid ester sulfates as an alternate excretory pathway was evaluated in hamsters. After bile duct ligation, total serum bile acid fell from a mean level of $454 \mu \mathrm{g} / \mathrm{ml}$ at $24 \mathrm{~h}$ to $64 \mu \mathrm{g} / \mathrm{ml}$ by $96 \mathrm{~h}$. During this period the bulk of the bile acid pool could be accounted for as esterified bile acids in urine. Renal pedicle ligation of animals with bile duct obstruction led to retention of the bile acid ester sulfates in serum. Thioacetamide hepatotoxicity diminished ester sulfation of bile acids causing diminished renal secretion with relatively greater retention of nonesterified bile acids in serum. We conclude that secretion of esterified bile acids by the kidney is an efficient alternate pathway for maintaining bile acid excretion in obstructive biliary tract disease. Coexistent hepatocellular disease diminishes ester sulfation and the effectiveness of the alternate pathway in maintaining bile acid excretion.
\end{abstract}

\section{INTRODUCTION}

In the last several years it has become apparent that all conjugated bile acids in man can be metabolized to ethereal sulfates $(1-3)$ and perhaps glucuronides (4) that are excreted in urine to a much greater extent than the nonesterified conjugates. This alternate pathway of renal excretion occurs in acute hepatitis, cirrhosis, extrahepatic obstruction, and a variety of intrahepatic cholestatic syndromes (5).

The significance of this alternate pathway is difficult to evaluate quantitatively. Thus far, studies have been done in heterogeneous populations at a single point in time during the course of a variety of diseases. Information of this type does not permit an evaluation

Dr. Galeazzi is a visiting postdoctorate fellow from the Division of Gastroenterology, General Hospital, Ancona, Italy.

Received for publication 21 January 1977 and in revised form 20 April 1977. of the quantitative aspects of an alternate pathway as a means of maintaining effective bile acid excretion. To provide guidelines on the quantitative significance of the alternate pathway of bile acid excretion, we have developed a hamster model that gives insights which may be applicable to man.

\section{METHODS}

Bile acids and bile acid sulfates. Bile acids in serum, bile, and urine were quantitatively estimated by gas-liquid chromatography $(\mathrm{GLC})^{1}$ as their methyl ester acetate derivatives with recrystallized $3 \alpha, 7 \alpha$-dihydroxy, 12-Keto $5 \beta$-cholanoate (Schwarz Mann Div. Becton, Dickinson Co., Orangeburg, N. Y.) as an internal standard as described in detail previously (6). Response factors for bile acids were established with chromatographically pure bile acids obtained from Supelco Inc., Bellefonte, Pa.

For quantitative estimation of bile acid ester sulfates, certain modifications are required. An ester sulfate internal standard was prepared from $3 \alpha$-hydroxy, 7 -Keto $5 \beta$-cholanoate (Steraloids, Inc., Pawling, N. Y.) by conversion to the methyl ester followed by reaction with a mixture of pyridinechlorsulfonic acid, a standard procedure for sulfation (7). The compound was purified by acidification of the reaction mixture, extraction into $n$-butanol, evaporation to dryness, and recrystallization from ethanol-water to give a product that was chromatographically homogenous.

The taurine and glycine conjugates of the ester sulfate derivative were prepared using EEDQ as a coupling agent as described in detail by Lack (8).

For solvolysis, a 2:1 mixture of methanol acetone containing dry $\mathrm{HCl}$ was used according to the principles established by Burstein and Lieberman (9). In practice, this mixture is easily prepared by adding $0.1 \mathrm{ml}$ of concentrated $\mathrm{HCl}$ to a test tube containing $1 \mathrm{ml}$ of $\mathrm{H}_{2} \mathrm{O}$ and $7.5 \mathrm{ml}$ of dimethoxypropane (Aldrich Chemical Co., Inc., Milwaukee, Wis.). Under these conditions all the water reacts quantitatively with the dimethoxypropane to yield the mixture described above (10).

With this solvolysis procedure, equal amounts of both internal standards were weighed and dissolved in methanol $(200 \mu \mathrm{g} / \mathrm{ml}$ were added to four tubes containing $1 \mathrm{ml}$ of

\footnotetext{
${ }^{1}$ Abbreviation used in this paper: GLC, gas-liquid chromatography.
} 
normal serum). Solvolysis was achieved by adding $7.5 \mathrm{ml}$ of dimethoxypropane and $0.1 \mathrm{ml}$ of concentrated $\mathrm{HCl}$ and allowing it to stand at $20^{\circ} \mathrm{C}$ for $60 \mathrm{~min}$. The samples were then processed in the standard manner for GLC analysis. It was found that the peak area of the recovered $3 \alpha$-OH, 7 -Keto $5 \beta$-cholanoate varied from 83 to $87 \%$ of the peak area of $3 \alpha, 7 \alpha$-dihydroxy, 12 -Keto $5 \beta$-cholanoate, a relationship not significantly different from that obtained with both chenodeoxycholic and nonsulfated $3 \alpha-\mathrm{OH}, 7-\mathrm{Keto} 5 \beta$ cholanoate. Thus solvolysis and recovery were considered to be virtually complete. The difference in peak area is attributable to different mass to peak ratios using a flame ionization detector that is corrected by an appropriate response factor.

It has been shown that solvolysis followed by alkaline hydrolysis is the preferred method for generating the unconjugated bile acids. Alkaline hydrolysis of sulfated bile acids can yield artifactual derivatives that do not occur when solvolysis is done before alkaline hydrolysis $(11,12)$. To further test these reports, the glycine and taurine conjugates of the ester sulfate $3 \alpha-\mathrm{OH}, 7$-Keto $5 \beta$-cholanoate were subjected to solvolysis followed by alkaline hydrolysis and also in reverse order. With the preferred method, recovery of both conjugates run in triplicate ranged from 82 to $85 \%$ indicating that the solvolysis procedure is applicable to conjugates and that alkaline hydrolysis is virtually complete. Solvolysis done after alkaline hydrolysis did not result in the appearance of unidentified peaks on the GLC tracing but recovery ranged from 77 to $83 \%$. It is possible that losses occur because the unconjugated sulfated bile acid does not extract as readily into the organic phase after hydrolysis and acidification. However, the possibility of artifactual compounds that did not appear as peaks in the GLC tracing cannot be excluded.

The possibility that hydrolysis of bile acid glucuronides could occur during the solvolysis procedure was evaluated by subjecting nitophenyl sulfate and phenolphthalein glucuronide (Sigma Chemical Co., St. Louis, Mo.) to both solvolysis and alkaline hydrolysis. After solvolysis and alkalinization, free nitophenol was readily detected (yellow) but no phenolphthalein (pink) was visible. However after solvolysis and alkaline hydrolysis, phenolphthalein could be demonstrated, indicating that some alkaline hydrolysis of ether glucuronides can occur although acid hydrolysis is the preferred method. From a technical point of view, it should be remembered that heating phenolphthalein glucuronide in $1.25 \mathrm{~N} \mathrm{NaOH}$ will not produce a visible pink color because the trisodium salt is colorless. However, acidification followed by alkalinization generates the pink color of the disodium salt. For these reasons, attempting to detect alkaline hydrolysis of phenolphthalein glucuronide can give a false negative result.

To determine the proportion of ester sulfates in biological samples, the double internal standard was added and only a portion of the sample subjected to solvolysis. Nonsolvolyzed samples, not subjected to alkaline hydrolysis, showed only one internal standard peak on GLC analysis. Nonsolvolyzed samples undergoing alkaline hydrolysis (1.25 N NaOH, $121^{\circ} \mathrm{C}, 3 \mathrm{~h}$ ) yielded a $3 \alpha$-hydroxy, 7 -Keto $5 \beta$-cholanoate peak between 3 and $5 \%$ of the $3 \alpha, 7 \alpha$-dihydroxy, 12-Keto $5 \beta$ cholanoate internal standard, indicating that some solvolysis can occur during chemical hydrolysis.

The percent ester sulfate for each bile acid in the sample was calculated from the difference in concentration between the solvolyzed and nonsolvolyzed sample corrected by the percent of the ester sulfate internal standard measured in the nonsolvolyzed sample.
Bile acid glucuronides. Urine collected from three hamsters for $24 \mathrm{~h}$ after bile duct ligation was pooled, concentrated, and analyzed for the presence of ether glucuronides and sulfates. Bacterial $\beta$-glucuronidase (Sigma Chemical Co.) and 1-4 saccharolactone were used as described in detail previously (13) and phenolphthalein glucuronide was used to verify the occurrence or inhibition of enzyme catalysis.

Aliquots of urine were incubated in acetate buffer $(\mathrm{pH} 4.5)$ with $\beta$-glucuronidase with or without saccharolactone followed by solvolysis and then hydrolysis of the conjugates using cholylglycine hydrolase (14). Analysis by GLC indicates that the maximum increase in bile acid concentration after $\beta$-glucuronidase was $12 \pm 3 \%$, a value that agrees with a mean value of $16 \%$ glucuronides found in human urine (15).

Analysis of the pooled urine for the proportion of bile acids as ester sulfates gave a value of $67 \pm 9 \%$ again indicating that the bile acid ester composition of hamster and human urine after extrahepatic obstruction is quite similar (5).

Inasmuch as many ethereal glucuronides are known to hydrolyze in alkali (16), the possibility that hydrolysis of bile acid glucuronides occurs during the chemical procedure used to hydrolyze conjugated bile acids $\left(1.25 \mathrm{M} \mathrm{NaOH} 121^{\circ} \mathrm{C}\right.$, $3 \mathrm{~h}$ ) was investigated. Human urine from three patients with intrahepatic cholestasis was pooled and concentrated. 4 aliquots were solvolyzed and only two were then incubated with $\beta$-glucuronidase. All the aliquots then underwent alkaline hydrolysis to cleave the conjugates. No significant difference in the concentration of deoxycholic, chenodeoxycholic, and cholic acids was found in any of the aliquots. It appears therefore that alkaline hydrolysis may also hydrolyze at least some bile acid glucuronides although the glucuronide of $3 \beta$-hydroxyandrost-5en-17-one, a sterol which might be expected to react similarly to bile acid glucuronides, was not hydrolyzed. The combination of solvolysis and alkaline hydrolysis probably permits analysis of virtually all the known bile acid derivatives in urine.

Bile acid pool size. The pool size of chenodeoxycholate and cholate was determined using ${ }^{14} \mathrm{C}-24$ labeled bile acids (Amersham/Searle Corp., Arlington Heights, IIl.) by modification of the method described by Adler (17). Exactly $0.1 \mathrm{ml}$ of $0.9 \%$ saline containing $2.5 \%$ human serum albumin and a mixture of trace amounts of ${ }^{14} \mathrm{C}-24$ chenodeoxycholate and cholate was injected into the jugular vein using a Hamilton syringe under brief ether anesthesia. At $24 \mathrm{~h}$, bile was aspirated from the gallbladder and biliary tree, and the specific activity of each bile acid determined after hydrolysis and thin-layer chromatography by GLC and liquid scintillation spectrometry by standard techniques previously described in detail (18).

Serum bilirubin, urea nitrogen, creatinine, and urine creatinine. These analyses were done in the pediatric biochemistry laboratory by standard micro methods under the supervision of the director, Dr. Edward Schubert.

Animals. Random bred male and female hamsters weighing between 100 and $120 \mathrm{~g}$ and maintained on a standard rodent pellet diet were used. For quantitative collection of urine, the animals were kept in metabolic cages with wire mesh tented screens to separate feces from urine. The feces were removed at 24 -h intervals, and by using a wash bottle with a thin jet stream, the sides of the collecting pans were rinsed with $30-40 \mathrm{ml}$ of distilled water that drained into the flask containing the urine. The total volume was measured and an aliquot taken for creatinine analysis. The remainder was percolated through a column of XAD-2 resin, and the bile acids then eluted with methanol. Aliquots of the methanol fraction were then used for quantitative bile acid analysis. 
Experimental design. The purpose of the study was to evaluate the quantitative importance of bile acid esterification and renal excretion in diseases of the liver and biliary tree.

Ligation of the hepatic ducts above the gallbladder under ether anesthesia was used to mimic biliary tract disease.

Hepatic cell necrosis was induced by intraperitoneal injection of thioacetamide $(20 \mathrm{mg} / 100 \mathrm{~g}$ body wt in $0.9 \%$ saline), a well-defined hepatotoxin that does not cause histological changes in other organs including the kidney (19). Animals on protein-depleted diets can develop elevation in urea nitrogen in serum in association with histologic renal lesions after several days of thioacetamide feeding (20). In the present studies, both serum creatinine, $0.6 \pm 1 \mathrm{mg} / 100$ $\mathrm{ml}$ and urea nitrogen $16.7 \pm 4.4 \mathrm{mg} / 100 \mathrm{ml}$ were found to remain unchanged during the $96-\mathrm{h}$ period of study in both male and female hamsters given thioacetamide. Also, histological sections of the kidney at the time of sacrifice showed no evidence of cell necrosis in contrast to the liver, which revealed the lesions described previously by others $(19,20)$.

Blood samples were obtained by heart puncture using brief ether anesthesia.

Serum bile acids and bile acid excretion in urine were estimated in a group of control male and female hamsters exposed to daily repeated ether anesthesia and aspiration of $0.4 \mathrm{ml}$ of blood by heart puncture. The total serum bile acid in seven hamsters was found not to exceed $2.2 \mu \mathrm{g} / \mathrm{ml}$.

The effect of renal pedicle ligation on serum bile acids was also determined in 10 animals up to $72 \mathrm{~h}$. It was found that the serum bile acid increased from a mean of $1.0 \mu \mathrm{g} / \mathrm{ml}$ at $24 \mathrm{~h}$ to a mean of $5.2 \mu \mathrm{g} / \mathrm{ml}$ at $72 \mathrm{~h}$. Although an occasional animal survived to $96 \mathrm{~h}$, none did in this group.

It was concluded from these preliminary studies that repeated ether anesthesia had no effect on serum bile acid levels, and that the effects of renal pedicle ligation alone were minimal and perhaps attributable to the effect of uremia on hepatic extraction efficiency of bile acids.

\section{RESULTS}

\section{Effect of bile duct ligation on bile acid metabolism and excretion}

Total serum bile acid levels were determined at $24-\mathrm{h}$ intervals for $96 \mathrm{~h}$ after bile duct ligation (Fig. 1). In 18 hamsters at $24 \mathrm{~h}$ the mean value was $454 \pm 176 \mu \mathrm{g} / \mathrm{ml} \mathrm{SD}$ and fell to $73 \pm 48 \mu \mathrm{g} / \mathrm{ml} \mathrm{SD}$. Cholic acid ranged from 61 to $86 \%$ and chenodeoxycholate from 10 to $31 \%$. These two primary bile acids always accounted for at least $90 \%$ of the total bile acids in serum.

During the 96-h period while bile acid levels were falling progressively, serum bilirubin rose from a mean value of 64 to $133 \mu \mathrm{g} / \mathrm{ml}$.

In 10 hamsters, total bile acid excretion in urine was determined at 24-h intervals (TableI). The excretion of bile acids in urine was greatest during the initial 24-h period and fell progressively during the $96-\mathrm{h}$ period. The total amount of bile acid excreted in urine probably represents the bulk of the primary bile acid pool of these animals (Table II) which was found to range from 4.9 to $12.9 \mathrm{mg}$, of which cholic acid was found to represent $51-71 \%$. Deoxycholate did not exceed $11 \%$ of the proportion of bile acids found in bile.

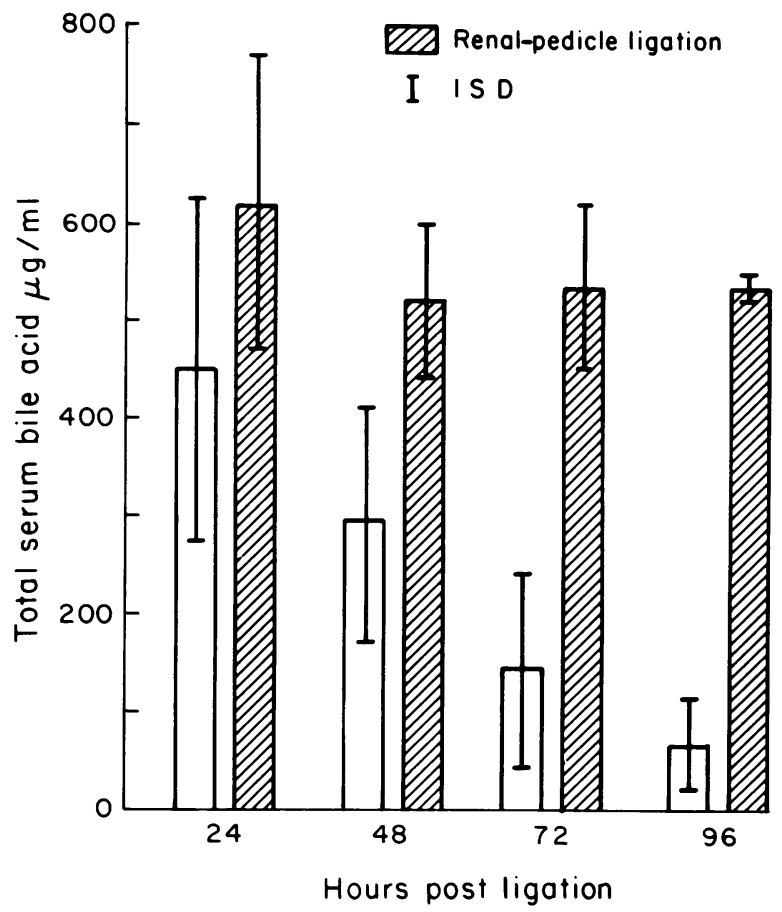

FIGURE 1 Total serum bile acid concentration in hamsters after duct ligation. 26 hamsters underwent bile duct ligation, of which 8 animals also had bilateral renal pedicle ligation (hatched bars). 0.4-ml aliquots of blood were collected by heart puncture at 24 -h intervals. A progressive fall in serum bile acids occurs in animals without renal pedicle ligation (open bars).

Bile acid ester sulfates in serum, urine, and hepatic bile after bile duct ligation. The proportion of ester sulfates in serum and in urine were analyzed at 24-h intervals in two hamsters (Table III). In all instances the proportion of ester sulfates in urine for each bile acid exceeded that found in serum. As the total serum bile acid fell progressively during the $96-\mathrm{h}$ period, a reduction in the proportion of ester sulfates in serum usually occurred.

The proportion of bile acid ester sulfates in bile obtained from distended hepatic ducts proximal to the ligature was also estimated (Table IV) at $96 \mathrm{~h}$ and found to be greater than that normally found in bile but much less than that found in urine.

\section{Renal pedicle ligation in bile duct obstructed animals}

Eight hamsters underwent bilateral renal pedicle ligation at the time of bile duct ligation. Only five survived for $72 \mathrm{~h}$ and two for $96 \mathrm{~h}$. As shown in Fig. 1, in the absence of renal excretion, the serum levels remain markedly elevated. Analysis of the proportion of sulfates in serum (Table V) indicates that con- 
TABLE I

Total Bile Acid Excretion in Urine of Hamsters after Bile Duct Ligation

\begin{tabular}{|c|c|c|c|c|c|c|c|c|c|}
\hline \multirow[b]{3}{*}{ Hamster no. } & \multicolumn{8}{|c|}{ Hours after obstruction } & \multirow{3}{*}{$\frac{\text { Total }}{\text { Bile acid }}$} \\
\hline & \multicolumn{2}{|c|}{24} & \multicolumn{2}{|c|}{48} & \multicolumn{2}{|c|}{72} & \multicolumn{2}{|c|}{96} & \\
\hline & Bile acid & Creatinine & Bile acid & Creatinine & Bile acid & Creatinine & Bile acid & Creatinine & \\
\hline & $\mu \mathrm{g} / \mathrm{mg} /$ creat $^{*}$ & $m g / 24 h$ & $\mu g / m g / c r e a t$ & $m g / 24 h$ & $\mu \mathrm{g} / \mathrm{mg} / \mathrm{creat}$ & $m g / 24 h$ & $\mu \mathrm{g} / \mathrm{mg} / \mathrm{creat}$ & $m g / 24 h$ & $m g / 96 h$ \\
\hline 1 & 1,280 & 2.1 & 952 & 2.4 & 234 & 2.1 & 177 & 3.2 & 6.1 \\
\hline 2 & 1,060 & 2.6 & 432 & 2.5 & 164 & 2.1 & 226 & 3.2 & 4.9 \\
\hline 3 & 870 & 3.8 & 325 & 3.3 & 321 & 3.5 & 430 & 3.4 & 7.0 \\
\hline 4 & 542 & 2.4 & 505 & 2.9 & 249 & 2.6 & 64 & 3.0 & 3.6 \\
\hline 5 & 639 & 3.1 & 389 & 2.9 & 242 & 3.2 & 60 & 2.8 & 4.1 \\
\hline 6 & 952 & 3.4 & 325 & 3.7 & 162 & 3.2 & 89 & 3.4 & 5.2 \\
\hline 7 & 780 & 3.7 & 301 & 3.5 & 172 & 3.2 & 128 & 3.7 & 5.1 \\
\hline 8 & 667 & 3.9 & 160 & 3.7 & 172 & 3.6 & 100 & 3.6 & 4.2 \\
\hline 9 & 570 & 3.4 & 335 & 3.0 & 148 & 2.9 & 100 & 2.4 & 3.5 \\
\hline 10 & 415 & 3.8 & 284 & 3.6 & 199 & 3.0 & 165 & 3.2 & 3.7 \\
\hline Mean $\pm S D$ & $778 \pm 265$ & & $400 \pm 214$ & & $206 \pm 54$ & & $153 \pm 100$ & & $4.7 \pm 1.1$ \\
\hline
\end{tabular}

* Creatinine.

siderable sulfation has occurred in the absence of a renal circulation. The proportion of sulfates found in serum in renal pedicle ligated animals is greater than in those with only bile duct obstruction.

\section{Effect of thioacetamide on bile acid metabolism}

Eight hamsters were given two intraperitoneal injections of thioacetamide at an interval of $24 \mathrm{~h}$ which caused elevation of the serum bile acids during the 96-h period of observation (Fig. 2). The mean total serum bile acid rose from $31 \mu \mathrm{g} / \mathrm{ml}$ at $24 \mathrm{~h}$ to $75 \mu \mathrm{g} / \mathrm{ml}$ at $96 \mathrm{~h}$.

The administration of thioacetamide to six animals with obstructed bile ducts was followed by marked persistent elevation of serum bile acids (Fig. 2) equivalent in some instances to those occurring in animals having combined renal pedicle and bile duct ligation (Fig. 1).

TABLE II

Primary Bile Acid Pool Size in Hamsters*

\begin{tabular}{cccc}
\hline Hamster & Chenodeoxycholate & Cholate & Total \\
\hline & $m g$ & $m g$ & $m g$ \\
1 & 2.8 & 6.8 & 9.6 \\
2 & 4.4 & 4.9 & 9.3 \\
3 & 2.1 & 2.8 & 4.9 \\
4 & 3.8 & 9.1 & 12.9 \\
5 & 4.2 & 7.1 & 11.3 \\
Mean \pm SD & $3.5 \pm 0.98$ & $6.1 \pm 2.4$ & $9.6 \pm 3.0$ \\
\hline
\end{tabular}

* Determined by isotope dilution at $24 \mathrm{~h}$.
Analysis of the proportion of ester sulfates in serum at $48 \mathrm{~h}$ failed to detect any sulfate conjugates of cholic acid (Fig. 3). The proportion of esterified chenodeoxycholate ranged from 10 to $44 \%$. Total bile acid excretion in the urine of bile duct ligated animals was significantly less during the 24 -h period after bile duct ligation in the animals given thioacetamide (Fig. 4). However, the proportion of bile acid ester sulfates in urine in thioacetamide-treated animals is not significantly different from those with only bile duct obstruction (Table VI).

\section{DISCUSSION}

Previous studies have shown that bile acid synthesis in the hamster is more similar to man than to the mouse or rat. Thus, the hamster, unlike the rat or mouse does not synthesize muricholic acids from cholesterol, 26 -hydroxycholesterol or $7 \alpha$-hydroxycholesterol (18, 21 ) and similar to man, has a bile acid pool consisting of mostly the glycine and taurine conjugates of cholic and chenodeoxycholic acids with lesser amounts of deoxycholate and lithocholate.

The quantitative significance of ester sulfation as an alternate pathway of bile acid excretion in the hamster is quite striking. Thus the bulk of the bile acid pool is excreted in urine within 4 days after bile duct ligation. More than $70 \%$ of the bile acids in urine were ester sulfates. In addition, glucuronides may account for as much as an additional $12 \%$. Thus, excretion of nonesterified bile acids is extremely limited in the hamster, as it is in man (22).

In the bile duct ligated hamster the proportions of 
TABLE III

Bile Acid Composition of Serum and Urine in Two Hamsters after Bile Duct Ligation

\begin{tabular}{|c|c|c|c|c|c|c|c|c|c|}
\hline \multirow{2}{*}{$\begin{array}{c}\text { Hours } \\
\text { postligation }\end{array}$} & \multirow[b]{2}{*}{ Source } & \multicolumn{4}{|c|}{ Bile acid } & \multicolumn{4}{|c|}{ Sulfate } \\
\hline & & Cholic & Cheno & Deoxy & Litho, & Cholic & Cheno & Deoxy & Litho \\
\hline & & & c & & & & & & \\
\hline \multicolumn{10}{|l|}{ I } \\
\hline \multirow[t]{2}{*}{24} & Serum & 68 & 26 & 0 & 6 & 23 & 51 & - & 0 \\
\hline & Urine & 85 & 5 & 10 & 0 & 86 & 95 & 100 & - \\
\hline \multirow[t]{2}{*}{48} & Serum & 68 & 28 & 0 & 6 & 18 & 35 & - & 0 \\
\hline & Urine & 75 & 19 & 1 & 5 & 80 & 80 & 37 & 100 \\
\hline \multirow[t]{2}{*}{72} & Serum & 77 & 20 & 0 & 3 & 0 & 35 & - & 0 \\
\hline & Urine & 64 & 27 & 0 & 9 & 77 & 85 & - & 100 \\
\hline \multirow[t]{2}{*}{96} & Serum & 72 & 28 & 0 & 0 & 10 & 8 & - & - \\
\hline & Urine & 72 & 16 & 2 & 0 & 35 & 75 & 100 & - \\
\hline \multicolumn{10}{|l|}{ II } \\
\hline \multirow[t]{2}{*}{24} & Serum & 77 & 16 & 3 & 4 & 18 & 46 & 44 & 0 \\
\hline & Urine & 76 & 18 & 6 & 0 & 88 & 78 & 100 & - \\
\hline \multirow[t]{2}{*}{48} & Serum & 76 & 19 & 0 & 5 & 18 & 45 & - & 0 \\
\hline & Urine & 76 & 20 & 0 & 4 & 54 & 92 & - & 100 \\
\hline \multirow[t]{2}{*}{72} & Serum & 83 & 17 & 0 & 0 & 27 & 18 & - & - \\
\hline & Urine & 85 & 15 & 0 & - & 50 & 88 & - & 100 \\
\hline \multirow[t]{2}{*}{96} & Serum & 82 & 18 & 0 & 0 & 0 & 0 & - & - \\
\hline & Urine & 78 & 22 & 0 & 0 & 76 & 70 & - & - \\
\hline
\end{tabular}

ester sulfates in serum were considerably higher at $24 \mathrm{~h}$ than at $72 \mathrm{~h}$. During this period the serum bile acid fell progressively as a consequence of renal excretion. The marked increase in esterified serum bile acids in the normal hamster in the 24 -h period after bile duct ligation indicates that their renal clearance is less than the rate of formation. Under these circumstances, renal clearance may be the rate-limiting step in the alternate pathway. However, lesser degrees of biliary obstruction may be associated with lower rates of esterification, and under these circumstances all the esterified bile acids could be rapidly excreted in urine.

A comparison was made of the proportions of ester sulfates in the serum of bile duct ligated hamsters that had, in addition, either bilateral renal pedicle ligation or ureteral ligation. Although no marked differences were noted, it was decided that the experimental design did not permit a quantitative statement concerning the possible role of the kidney in the sulfation of bile acids (23).

The proportions of bile acid ester sulfates in serum

TABLE IV

Bile Acid Composition of Bile in Five Hamsters 24 h after Bile Duct Ligation*

\begin{tabular}{|c|c|c|c|c|c|c|c|c|c|}
\hline \multirow[b]{2}{*}{ Hamstert } & \multirow{2}{*}{$\begin{array}{c}\text { Total bile } \\
\text { acid }\end{array}$} & \multicolumn{4}{|c|}{ Bile acid } & \multicolumn{4}{|c|}{ Sulfate } \\
\hline & & Cholic & Cheno & Deoxy & Litho & Cholic & Cheno & Deoxy & Litho \\
\hline & $m g / m l$ & \multicolumn{4}{|c|}{ " } & \multicolumn{4}{|c|}{$"$} \\
\hline 1 & 20.2 & 79 & 17 & 3 & 1 & 3 & 0 & 0 & 14 \\
\hline 2 & 6.8 & 85 & 15 & 0 & 0 & 0 & 25 & 0 & 0 \\
\hline 3 & 12.6 & 68 & 25 & 5 & 2 & 9 & 22 & 0 & 2 \\
\hline 4 & 44.2 & 66 & 23 & 10 & 1 & 9 & 0 & 0 & 0 \\
\hline 5 & 23.8 & 66 & 26 & 4 & 4 & 5 & 0 & 0 & 33 \\
\hline 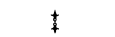 & $35.3 \$$ & 72 & 15 & 10 & 3 & 0 & 0 & 0 & 60 \\
\hline
\end{tabular}

* Bile aspirated at the time of sacrifice from distended hepatic ducts.

$\$$ Pooled gallbladder bile from five normal hamsters. 
TABLE V

Proportion of Bile Acids and Percent Sulfated in Serum after Ligation of Bile Duct and Renal Pedicles in Two Hamsters

\begin{tabular}{|c|c|c|c|c|c|c|c|c|}
\hline \multirow{2}{*}{$\begin{array}{c}\text { Hours } \\
\text { postligation }\end{array}$} & \multicolumn{4}{|c|}{ Bile acid } & \multicolumn{4}{|c|}{ Sulfate } \\
\hline & Cholic & Cheno & Deoxy & Litho & Cholic & Cheno & Deoxy & Litho \\
\hline & \multicolumn{4}{|c|}{$\%$} & \multicolumn{4}{|c|}{$\%$} \\
\hline \multirow[t]{2}{*}{24} & 78 & 18 & 3 & 1 & 61 & 12 & 100 & 100 \\
\hline & 82 & 10 & 4 & 4 & 46 & 71 & 49 & 84 \\
\hline \multirow[t]{2}{*}{48} & 76 & 18 & 4 & 2 & 81 & 77 & 100 & 85 \\
\hline & 79 & 19 & 3 & 4 & 38 & 34 & 79 & 100 \\
\hline \multirow[t]{2}{*}{72} & 84 & 10 & 2 & 4 & 84 & 75 & 35 & 74 \\
\hline & 64 & 31 & 2 & 3 & 38 & 59 & 35 & 80 \\
\hline \multirow[t]{2}{*}{96} & 73 & 21 & 3 & 3 & 81 & 55 & 43 & 100 \\
\hline & 73 & 20 & 4 & 3 & 51 & 29 & 100 & 100 \\
\hline
\end{tabular}

are somewhat difficult to interpret quantitatively because of a possible recirculation of unesterified bile acids from the obstructed bile ducts. It was noted at the time of sacrifice that the bile ducts above the site of obstruction were distended even at $96 \mathrm{~h}$. The bile acid concentration of this fluid was similar to normal hepatic bile but in addition contained esterified bile acids at relatively low concentrations compared to urine. Thus a reservoir of unesterified bile acids could have been recirculating episodically during the 96 -h period of

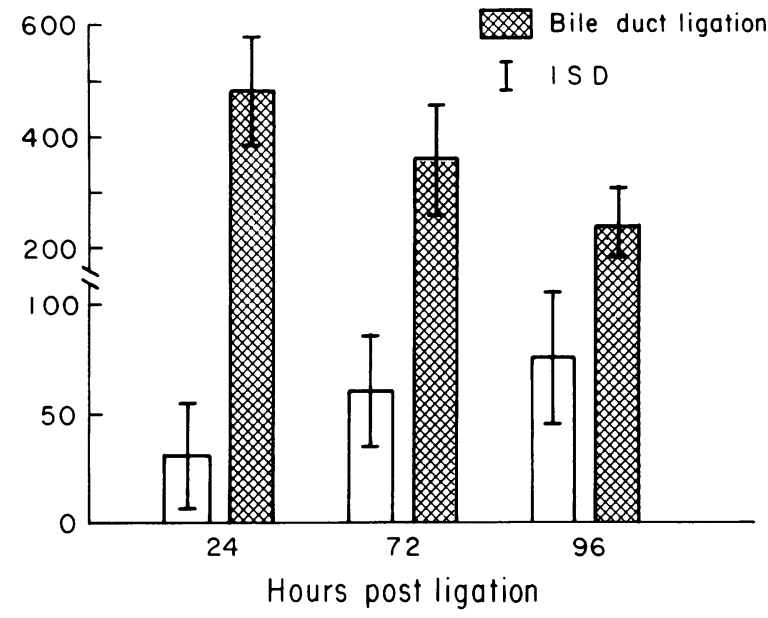

FIgURE 2 Total serum bile acid concentration in hamsters after thioacetamide administration. 14 hamsters received two intraperitoneal injections of thioacetamide $(20 \mathrm{mg} / 100 \mathrm{~g}$ body wt) at 0 and $24 \mathrm{~h}$. Six animals also had bile duct ligation at the time of the initial thioacetamide administration. Thioacetamide alone caused a progressive increase in serum bile acids that exceeded levels found in bile duct ligated animals at $96 \mathrm{~h}$ (Fig. 1). Bile duct ligation of thioacetamidetreated animals (cross-hatched bars) caused a much greater increase in serum bile acids.
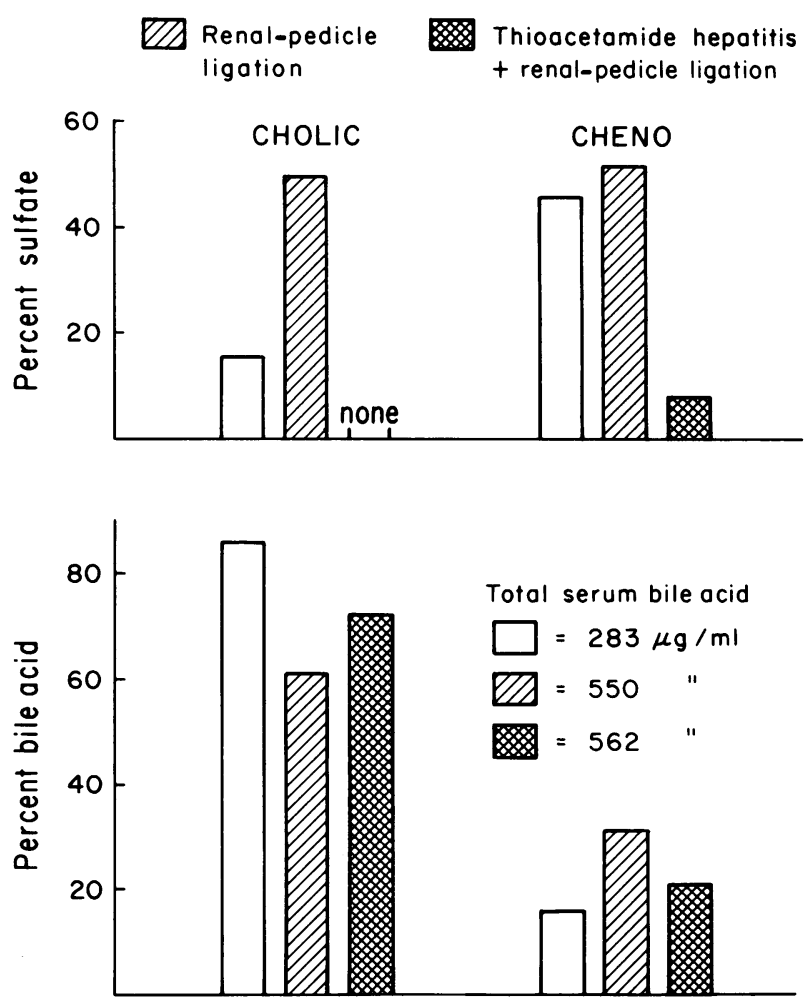

FIGURE 3 Serum bile acid concentrations and proportions of chenodeoxycholate and cholate and percent esterified as sulfate in hamsters with bile duct ligation. Typical results are shown in three animals studied at $48 \mathrm{~h}$. One hamster (open bar) had bile duct ligation and the total serum bile acid $(283 \mu \mathrm{g} / \mathrm{ml})$ is less than the other two animals, both of whom had renal-pedicle ligation. In addition, one animal (cross-hatch) received thioacetamide. The proportion of ester sulfates in serum is significantly less in the animal with thioacetamide hepatitis. The animal with intact kidneys (open bars) has a lower serum bile acid and lower proportion of esterified cholate attributable to urinary excretion. 
TABLE VI

Proportion of Bile Acids in Urine and Percent Sulfated in Two Hamsters after Bile Duct Ligation and Thioacetamide Administration

\begin{tabular}{|c|c|c|c|c|c|c|c|c|}
\hline \multirow{2}{*}{$\begin{array}{c}\text { Hours } \\
\text { postligation }\end{array}$} & \multicolumn{4}{|c|}{ Bile acid } & \multicolumn{4}{|c|}{ Sulfate } \\
\hline & Cholic & Cheno & Deoxy & Litho & Cholic & Cheno & Deoxy & Litho, \\
\hline & \multicolumn{4}{|c|}{$\%$} & \multicolumn{4}{|c|}{$\%$} \\
\hline \multirow[t]{2}{*}{24} & 80 & 16 & 3 & 1 & 70 & 16 & 44 & 100 \\
\hline & 77 & 14 & 3 & 6 & 78 & 14 & 100 & 84 \\
\hline \multirow[t]{2}{*}{48} & 71 & 21 & 3 & 2 & 65 & 21 & 100 & 100 \\
\hline & 77 & 22 & 0 & 0 & 52 & 22 & - & - \\
\hline \multirow[t]{2}{*}{72} & 72 & 23 & 0 & 4 & 82 & 23 & - & 100 \\
\hline & 56 & 19 & 2 & 5 & 53 & 19 & 89 & 100 \\
\hline \multirow[t]{2}{*}{96} & 69 & 26 & 0 & 4 & 70 & 26 & - & 100 \\
\hline & 58 & 32 & 4 & 6 & 69 & 50 & 100 & 63 \\
\hline
\end{tabular}

study and could have affected the proportions of ester sulfates in plasma. The magnitude of this problem is greater if bile duct ligation is done below the gallbladder, and it is therefore important to ligate as high as possible above the gallbladder. Nevertheless, the marked difference in the proportions of ester sulfates in bile duct ligated animals at $24 \mathrm{~h}$ and $96 \mathrm{~h}$ indicates that in biliary tract obstruction, the synthesis of ester sulfates can exceed their renal clearance in the hamster. The wide range in serum bile acid concentration after bile duct ligation can be attributed to the difference in bile acid pool size, the proportion present in bile ducts and the rate of excretion in urine.

Further quantitative assessment of the significance of esterification can be obtained from the use of a well-defined hepatotoxin that does not affect the kidney (19). Confirmation of previous studies (20) was obtained by demonstrating normal renal morphology and normal serum creatinine during the $96 \mathrm{~h}$ of observations. The liver showed the characteristic changes previously described.

Administration of thioacetamide alone caused an increase in serum bile acids. At $96 \mathrm{~h}$ the serum bile acid elevations were in the range found for animals in which the bile duct was totally obstructed. However, the amount found in urine indicated relatively little renal excretion and there was relatively little esterified bile acid in serum.

The defect in esterification could be further evaluated by bile duct ligation of animals given thioacetamide. Total serum bile acids approximated levels seen in renal-pedicle ligated hamsters at $96 \mathrm{~h}$ but in contrast contained significantly less sulfate. The findings indicate that as part of the hepatotoxicity there is a reduction in the capacity to esterify bile acids and therefore a reduced renal clearance. For this reason, at comparable serum bile acid levels at 24 and $48 \mathrm{~h}$, bile acids excreted in urine in thioacetamide-treated animals is reduced (Fig. 4). Consistent with this interpretation is the unchanged proportion of bile acid esters in urine. Thus, the esterified bile acids are cleared by the kidney and the limiting step is the capacity to esterify bile acids.

These studies provide a convenient experimental model that can help to unravel the possible significance of the esterification of bile acids that occurs in the course of a variety of hepatic diseases in man. Unlike bilirubin which is excreted as the same metabolites in urine or bile, it appears that diminished capacity to excrete bile acid by the liver is associated with either the activation or diversion of enzymatic pathways to the esterification of bile acids. It would seem that the

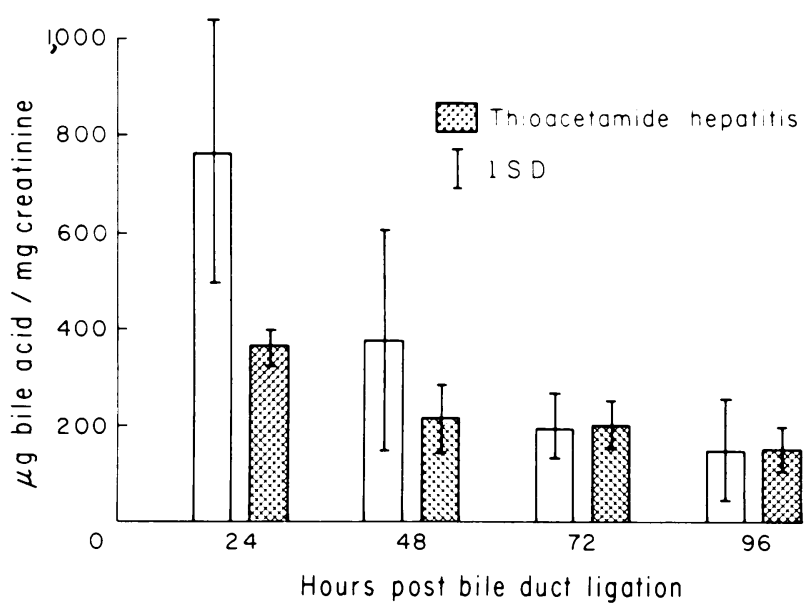

FIgUre 4 Total bile acid excretion in urine after bile duct ligation. 24 hamsters underwent bile duct ligation. In addition, six animals received injections of thioacetamide (crosshatched bars). Total bile acid excretion at $24 \mathrm{~h}$ is much greater in animals not having thioacetamide hepatitis (open bars). 
sulfokinase enzymes, about which very little is known, would play the major role in the pathway.

Some information is available concerning the biological role of sulfation of steroids in regard to hormone metabolism (24). It appears that the ester sulfation of hormones occurs mostly in liver, to some extent in intestines, and very little in kidney, except perhaps during the newborn period. Ester sulfation of hormones is known to markedly reduce or nullify their biologic activity.

Other than possible regulators of hepatic cholesterol and bile acid synthesis, it is not known whether bile acids have any biologic activity in regard to hepatocytes. In vitro data exist to indicate they have deleterious effects on enzymatic functioning (25). From studies of hepatic transport of bile acids (26), it is quite clear that an equilibrium occurs between the hepatocyte and serum in a manner known to occur for sulphobromophthalein and referred to as a "storage" phenomenon (27). Thus high intracellular concentrations of unesterified bile acids in cholestatic liver disease could affect hepatocyte function and be a determinant of the course of the disease. Ester sulfation by the hepatocyte could reduce these biologic effects and does enhance their renal excretion, thus reducing potential deleterious effects. Evidence already exists to indicate that the cholestatic effect of $3 \beta$-hydroxy- $5 \beta$-cholanoate (28) is prevented by ester sulfation $(29,30)$ and that the esterified form is preponderant both in urine (31) and meconium (32).

\section{ACKNOWLEDGMENTS}

This work was supported by grant AM 16201 from The National Institute of Arthritis, Metabolism, and Digestive Diseases.

\section{REFERENCES}

1. Makino, I., K. Shinozaki, and'S. Nakagawa. 1972. Sulfated bile acids in the urine of patients with hepatobiliary diseases. Lipids. 8: 47-49.

2. Stiehl, A. 1974. Bile salt sulfates in cholestasis. Eur. J. Clin. Invest. 4: 59-63.

3. Javitt, N. B., U. Lavy, and E. Kok. 1976. Bile acid balance studies in cholestasis. In The Liver: Quantitative Aspects of Structure and Function. R. Preisig, J. Bircher, and G. Paumgartner, editors. Editio Cantor, Aulendorf, W. Germany. 249-254.

4. Back, P., K. Spaczynski, and W. Gerok. 1974. Bile salt glucuronides in urine. Hoppe-Seyler's Z. Physiol. Chem. 355: 749-752.

5. Makino, I., H. Hashimoto, K. Shinozaki, K. Yoshino, and S. Nakagawa. 1975. Sulfated and nonsulfated bile acids in urine, serum and bile of patients with hepatobiliary diseases. Gastroenterology. 68: 545-553.

6. Ali, S. S., and N. Javitt. 1970. Quantitative estimation of bile salts in serum. Can. J. Biochem. 48: 1054-1057.

7. Palmer, R. H., and M. G. Bolt. 1971. Bile acid sulfates. I. Synthesis of lithocholic acid sulfates and their identification in human bile. J. Lipid Res. 12: 671-679.
8. Lack, L., F. O. Dorrity, Jr., T. Walker, and G. Singletary. 1973. Synthesis of conjugated bile acids by means of peptide coupling reagent. J. Lipid Res. 14: 367-370.

9. Burstein, S., and S. Lieberman. 1958. Kinetics and mechanism of solvolysis of steroid hydrogen sulfates. J. Am. Chem. Soc. 80: 5235-5239.

10. Critchfield, F. E., and E. T. Bishop. 1961. Water determination by reaction with 2,2-dimethoxypropane. Anal. Chem. 33: 1034-1035.

11. Eyssen, H. J., G. Parmentier, and J. A. Mertens. 1976. Sulfated bile acids in germ-free and conventional mice. Eur. J. Biochem. 66: 507-514.

12. Haslewood, E. S., and G. A. D. Haslewood. 1976. Preparation of the 3-monosulphates of cholic acid, chenodeoxycholic acid and deoxycholic acid. Biochem. J. 155: 401-404.

13. Javitt, N. B. 1966. Ethereal and acyl glucuronide formation in the homozygous Gunn rat. Am. J. Physiol. 211: 424-428.

14. Nair, P. P., M. Gordon, and J. Rebak. 1967. The enzymatic cleavage of the carbon-nitrogen bond in $3 \alpha, 7 \alpha, 12 \alpha$, -trihydroxy-5 $\beta$-cholan-24-oyl glycine. J. Biol. Chem. 242: $7-11$.

15. Frohling, W., and A. Stiehl. 1976. Bile salt glucuronides: identification and quantitative analysis in the urine of patients with cholelithiasis. Eur.J. Clin. Invest. 6: 67-74.

16. Whistler, R. L., and J. N. BeMiller. 1958. Alkaline degradation of polysaccharides. Adv. Carbohydr. Chem. 13: 289-329.

17. Duane, W. C., R. D. Adler, L. J. Bennion, and R. L. Ginsberg. 1975. Determination of bile acid pool size in man: a simplified method with advantages of increased precision, shortened analysis time, and decreased isotope exposure. J. Lipid Res. 16: 155-158.

18. Anderson, K. E., E. Kok, and N. Javitt. 1972. Bile acid synthesis in man: metabolism of $7 \alpha$-hydroxycholesterol${ }^{14} \mathrm{C}$ and 26 -hydroxycholesterol- ${ }^{3} \mathrm{H}$. J. Clin. Invest. $\mathbf{5 1}$ : $112-117$.

19. Ambrose, A. M., F. DeEds, and L. J. Rather. 1949. Toxicity of thioacetamide in rats. J. Ind. Hyg. Toxicol. 31: 158-161.

20. Hruban, Z., W. Gradman, A. Slesers, and M. Lubran. 1966. Toxicity of thioacetamide. Lab. Invest. 15: 1748-1760.

21. Wachtel, N., S. Emerman, and N. B. Javitt. 1969. Metabolism of cholest-5-ene-3 $\beta, 26$-diol in the rat and hamster. J. Biol. Chem. 243: 5207-5212.

22. Rudman, D., and F. E. Kendall. 1957. Bile acid content of human serum. I. Serum bile acids in patients with hepatic disease. J. Clin. Invest. 36: 530-537.

23. Summerfield, J. A., J. Z. Gollan, and B. H. Billing. 1976. Synthesis of bile acid monosulphates by the isolated perfused rat kidney. Biochem. J. 156: 339-345.

24. Lebeau, M. C., and E. E. Baulieu. 1973. On the significance of the metabolism of steroid hormone conjugates. In Metabolic Conjugation and Metabolic Hydrolysis. Vol. 3. W. Fishman, editor. Academic Press, New York. 151- 187.

25. Greim, H., D. Trulzsch, J. Rovoz, K. Dressler, P. Czygan, F. Hutterer, F. Schaffner, and H. Popper. 1972. Mechanisms of cholestasis: 5 bile acids in normal rat livers and in those after bile duct ligation. Gastroenterology. 63: $837-845$.

26. Reichen, J., and G. Paumgartner. 1976. Uptake of bile acids by perfused rat liver. Am. J. Physiol. 231: 734-742.

27. Wheeler, H. O., J. J. Meltzer, and S. E. Bradley. 1960. Biliary transport and hepatic storage of sulfobromophthalein sodium in the unanesthetized dog, in normal man, and in patients with hepatic disease. J. Clin. Invest. 39: 1131-1144. 
28. Emerman, S., and N. B. Javitt. 1968. Effect of sodium taurolithocholate on bile flow and bile acid excretion. J. Clin. Invest. 47: 1002-1014.

29. Javitt, N. B. 1973. Excretion of monohydroxy bile acid ester sulfates in the rat. In The Liver: Quantitative Aspects of Structure and Function. G. Paumgartner and R. Preisig, editors. S. Karger, Basel. 355-359.

30. Layden, T. J., J. Schwarz, and J. L. Boyer. 1975. Scanning electron microscopy of the rat liver: studies on the effect of taurolithocholate and other models of cholestasis. Gastroenterology. 69: 724-738.

31. Back, P. 1975. Identification and quantitative determination of urinary bile acids excreted in cholestasis. Clin. Chim. Acta. 44: 199-207.

32. Makino, I., J. Sjovall, A. Norman, and B. Strandvik. 1971. Excretion of $3 \beta$ hydroxy-5-cholenoic and $3 \alpha$ hydroxy-5cholenoic acids in urine of infants with biliary atresia. FEBS (Fed. Eur. Biochem. Soc.) Lett. 15: 161-164. 